\title{
An Overview of Dry Socket and Its Management
}

\author{
S. Preetha \\ Saveetha Dental College Ponamallee, Chennai
}

\begin{abstract}
Dry socket is one of the common complication after the removal of third molars. It occurs due to disruption of the clot within the socket. This article gives a brief overview about the clinical features, etiopathogenesis and the management of dry socket.
\end{abstract}

Key words: alveolar osteitis , fibrinolysis , management

\section{Introduction}

A dry socket also referred to as alveolar osteitis is a post operative complication that interferes with the healing process that takes place after a tooth extraction. Blum (2002) defined alveolar osteitis as "post operative pain inside and around the extraction site , which increases in severity at any time between the first and third day after the extraction ,accompanied by a partial or total disintegrated blood clot within the alveolar socket with or without halitosis". 1

"Dry socket" was first described by Crawford in $1896 .{ }^{2}$ The name dry socket is used because the socket has a dry appearance after the blood clot is lost and debris washed away. The other terms used are alveolar osteitis, alveolitis , localized osteitis, alveolitis sicca dolorosa, localized alveolar osteitis , fibrinolytic alveolitis , septic socket, necrotic socket, alveolagia. ${ }^{3}$ It occurs when the tooth socket loses the blood clot that forms after the tooth is extracted and the bone inside the socket is exposed. It occurs in $0.5-5 \%$ of routine dental extractions and $25-30 \%$ in extraction of impacted mandibular third molars. ${ }^{4}$

\section{Clinical Features}

Clinically , an empty socket which lacks a blood clot and exposed bone are seen. The socket may be filled with food debris and saliva mixture. ${ }^{4}$ Pain starts 24-72 hours after extraction. It varies in frequency and intensity and radiates to the ear and neck. ${ }^{5}$ Headache, insomnia and dizziness may be present. ${ }^{6}$ It is not characterized by redness, swelling, fever or pus formation but oedema of the surrounding gingiva and regional lymphadenitis is present. There is marked halitosis and foul taste. ${ }^{7,8}$

Histological features of dry socket is comprised of remenants of the blood clot and a massive inflammatory response characterized by neutrophils and lymphocyte which may extend into the surrounding alveolus. $^{9}$

\section{Etiopathogenesis}

Several theories have been proposed on the etiology of dry socket . They are trauma during extraction, bacterial infection and biochemical agents. ${ }^{10}$ Fibrinolysis is a normal physiological process that removes fibrin deposits by enzymatic digestion of the fibrin meshwork into smaller soluble fragments. Local increase in fibrinolysis occur in response to bleeding. ${ }^{11}$

Birn in 1973 showed that there is increased fibrinolytic activity in dry sockets and activation of plasminogen to plasmin in the presence of tissue activators. ${ }^{9}$ He also proposed that the increase in fibrinolysis decreased the chance of dissolution of the blood clot before the second day after surgery, because the clot contains antiplasmin, which must be neutralized before clot dissolution can occur. ${ }^{12}$

A fibrin clot is formed by thrombin and fibrinogen in a normal post extraction socket. Over this , the epithelium migrates. New blood vessels grow into the clot during granulation tissue formation and this clot degrades through the activity of fibroblast and fibrinolysis through the plasmin before the start of osteoproliferation. ${ }^{13}$ Birn discovered that the plasmin like activity in dry sockets was not present at normal extraction sites. ${ }^{14}$ Kinases are liberated during inflammation through direct or indirect activation of plasminogen in the blood. These kinases cause lysis and destruction of the blood clot. Tissue or plasma pro-activators and activators convert the plasminogen to fibrin , resulting in the dissolution of the clot by disintegration of fibrin. ${ }^{15}$ This plasminogen pathway activation, can be direct(physiologic) or indirect(non physiologic) activators. Direct activators are released to the alveolar bone cells after trauma. Indirect activators are released by bacteria. ${ }^{16,17}$ Direct extrinsic activators are tissue plasminogen activators and endothelial plasminogen activators. Direct intrinsic activators include the components of plasma such as factor XII , urokinase. Birn showed that the kinin in concentration as low as $1 \mathrm{mg} / \mathrm{ml}$ produce intense pain. ${ }^{18}$ 


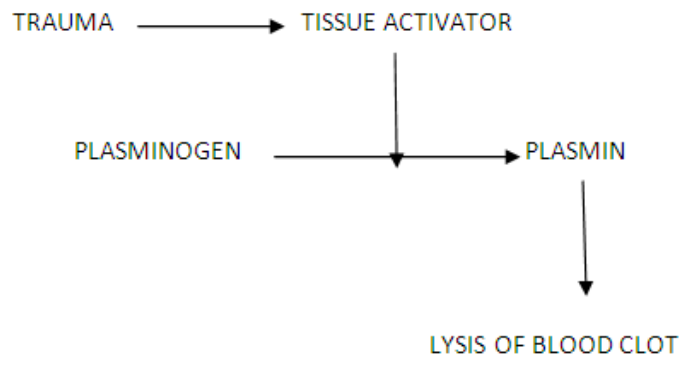

\section{Extraction Site}

\section{Predisposing Factors}

Dry sockets occur more frequently in the mandible than the maxilla due to thick cortical bone resulting in poor perforation of blood supply the mandible. It occurs more commonly in the extraction of the third molars. ${ }^{19}$

\section{Gender}

It occurs more frequently in females than males due to possible hormonal cause. Sweet and Butler(1938) reported that the incidence of dry socket in females is $4.1 \%$ compared to males. ${ }^{20}$

\section{Trauma}

Difficult extractions occur in older and dense bone which may have a decreased vascularity. Birn proposed that trauma from extraction and aggressive curettage cause the inflammation of the alveolar osseous medulla which leads to the release of cell mediators. This causes fibrinolytic activity. ${ }^{9}$

\section{Smoking}

Smoking reduce the neutrophil chemotaxis and phagocytosis thus impairing the production of immunoglobulin. ${ }^{21}$ Nicotine the active drug in tobacco is absorbed though the oral mucosa. This drug increases the platelet aggregation thereby increasing the risk of microvascular thrombosis and peripheral ischemia. Proliferation of fibroblast and macrophages is also inhibited. ${ }^{22}$

The incidence of dry socket was significantly higher in smokers (12\%) than in non-smokers (4\%), but, there is a strong association between the amount of smoking and the incidence of dry socket. ${ }^{23}$

\section{Vasoconstrictors}

Vasoconstrictors in the local anesthetics used for extraction may also contribute to the formation of dry socket. Vasocinstrictors cause temporary local ischemia which increase the risk of developing alveolar osteitis. $^{9,24}$

\section{Microorganisms}

Bacteria may also play a contributing factor in the etiology of dry socket. Delayed healing may occur due to the presence of microorganisms like Enterococcus, Streptococcus viridans, Bacillus coryneform, Proteus vulgaris, Pseudomonas aeruginosa, Citrobacter freundii, Escheria coli.

Nisan et al (1983) proposed that the anaerobic bacteria Treponema denticola showed plasminogen like fibrinolytic activity. ${ }^{3}$

\section{Oral Contraceptives}

Lily observed that the dry socket occurred three times more frequently in females on oral contraceptives than in those who were not taking them. Oral contraceptives elevate plasma fibrinolytic activity which affects the stability of the clot after extraction. They elevate the factors II, VII,VIII,X and plasminogen thereby increasing the lysis of blood clot. ${ }^{25}$

\section{Radiotherapy}

Radiotherapy to the head and neck results in a decreased blood supply to the mandible ${ }^{26}$

\section{Chlorhexidine}

\section{Prevention}

Chlorhexidine(CHX) is a bisguanide antiseptic which when used as a preoperative irrigant and mouthwash, reduce the quantity of oral microbiota. 
Field et al(1987) observed that there was a decreased incidence of dry socket after irrigation of the gingival crevice and two minute mouth rinse with $0.2 \%$ CHX digluconate in comparison with no irrigation or irrigation with saline. ${ }^{13}$

Study was conducted in a private practice setting to determine the effect of a $0.12 \%$ chlorhexidine gluconate rinse (Peridex, Proctor and Gamble, Cincinnati, Ohio) on the incidence of dry socket after removal of impacted mandibular third molars. Over a 3-year period, 371 patients (total of 654 impacted mandibular third molars) received either no treatment (group 1), 2 weeks of twice daily Peridex rinse postsurgery (group 2), or one rinse presurgery (group 3). The group that used Peridex twice daily for 2 weeks after surgery (group 2) showed a significant reduction $(56 \%)$ in the incidence of dry socket when compared with either the group that did not rinse (group 1) or the group that rinsed only once just before surgery (group 3 ). ${ }^{27}$

\section{Antibiotics}

Systemic and topical antibiotics influence the incidence of dry socket. ${ }^{28}$ Systemic antibiotics like Penicillin, Clindamycin, Erythromycin and Metronidazole are effective in prevention of dry socket. Use of topical tetracyclines has shown side effects along with foreign body reactions. ${ }^{17}$

\section{Antifibrinolytics}

Antifibrinolytics like traxanemic acid interfere with the formation of the fibrinolytic enzyme plasmin from its precursor plasminogen by plasminogen activators. ${ }^{17}$

\section{Antimicrobial Photo Dynamic Therapy(Apdt)}

Lower incidence of dry socket after antimicrobial photodynamic therapy seems to be a new and promising possibility for the prevention of alveolar osetitis.

In a study, the group with aPDT alveolar ostitis occurred at one extraction site and in the control group without aPDT in 13 cases, the subjective pain assessment on the day after tooth removal was scored with $11.2+/-9.8$ in the aPDT-group and with 19.0+/-12.2 in the control group. One week after extraction the pain sensation in the aPDT group was scored with $2.4+/-9.2$ and in the control group with $13.1+/-25.2$. The difference was significantly lower with $\mathrm{p}=0.000$ for the 1 st and 8 th post-surgical days in the aPDTgroup. ${ }^{29}$

\section{Low Level Laser Therapy(Lllt)}

LLLT increases the speed of wound healing and reduces inflammation when compared to Alvogyl and Salilept. It is used after the irrigation of socket as a continuous mode diode laser irradiation $(808 \mathrm{~nm}, 100 \mathrm{~mW}$, 60 seconds, $7.645 / \mathrm{cm}^{30}$

\section{Management}

Management of dry socket can be by irrigation, surgical intervention and placement of medicated dresssing.

\section{Irrigation}

Irrigation removes the debris, sequestra and bacteria from the denuded bone in the dry socket. ${ }^{31}$ The use of heated saline solution, powdered sodium perborate, gauze with iodoform, the prescription of codeine and subsequent irrigation with a concentrated solution of sodium perborated has been proposed in $1929 .{ }^{32}$ Home instructions for maintenance of oral hygiene and gentle warm saline rinses help in the healing of the socket. ${ }^{8}$

\section{Medicated Dressing}

Placement of medicated dressing is suggested as a combination with surgical intervention due to the occurrence of local complications. ${ }^{33}$ Turner proposed that packing of the socket could delay wound healing and increases the chance of infection. Fazakerley and Field suggested the removal of sutures and irrigation with warm saline under local anesthesia before the applicationof a medicated dressing containing zinc oxide and eugenol mixed into a semisolid consistency applied to an iodoform ribbon gauze. Every 2-3 days, the pack must be changed and removed after the pain subsides. ${ }^{13}$ Use of pertoleum based carriers is not recommeded due to myospherulosis. Some of the medicated dressings used are antibacterials, topical anesthetics and obtundants, or combinations of all three, e.g., zinc oxide and eugenol impregnated cotton pellets, alvogyl (eugenol, iodoform and butamen), dentalone, bismuth subnitrate and iodoform paste (BIPP) on ribbon gauze and metronidazole and lidocaine ointment. ${ }^{34}$

\section{Analgesics}

The choice of analgesics can range from a short course of non steroidal antiinflammatory drug to narcotic based like codeine. 


\section{Surgical Intervention}

Curretage can be used as a method of treatment for dry socket. However it is not recommended due to the induction of more pain. Curretage involves administration of anesthesia, surgical debridement of socket and primary closure by advancement flap. ${ }^{23}$ Turner stated that curretage and removal of granulation tissue resulted in fewer visits than zinc oxide eugenol or iodoform gauze with eugenol technique.

\section{Conclusion}

The occurrence of dry socket is unavoidable. It canbe prevented by copious use of irrigation, antibiotics and maintenance of oral hygiene. Although there is no specific treatment for dry socket eugenol dressings and curretage reduce the incidence of it.

\section{References}

[1]. Blum IR. Contemporary review on dry socket(alveolar osteitis):a clinical appraisal of standardization , aetiopathogenesis and management :a critical review. International Journal of Oral and Maxillofacial Surgery 2002;3(3):309-317 [Pub Med]

[2]. Crawford JY.Dry socket . Dental Cosmos. 1896;38:929-931

[3]. Cadoso CL, Rodrigues MT , Ferreira JO , Garlet GP , de Carvalho PS.Clinical concepts of dry socket .J Oral Maxillofac Surg 2010;68:1922-1932

[4]. Bowe DC, Rogers S , Stassen LF. The management of dry scocket/alveolar osteitis .J Ir Dent Assoc 2011;57:305-310

[5]. Swanson AE:A double blind study on the effectiveness of tetracycline in reducing the incidence of fibrinolytic alveolitis. J Oral Maxillfac Surg 47:165,1989

[6]. Sasaki T.Okamoto T:Topical treatment of infections of alveolar socket infections following dental extractions. Rev.Bras Odontol 25:82,1968

[7]. Awang MN.The aetiology of dry socket :a review .Int Dent J 1989;39:236-40

[8]. Fazakerley M.Field EA.Dry socket:A painful post extraction complication(a review).Dent Update 1991;18:31-4

[9]. Birn H. Etiology and pathogenesis in fibrinolytic alveolitis (dry socket). Int J Oral Surg 1973;2:211-63

[10]. Butler DP, Sweet JB.Effect of lavage on the incidence of localized osteitis in mandibular third molar extraction sites.Oral Surg Oral Med Oral Pathol Oral Radiol Endod 1977;44:14-20

[11]. Catellini JE.Review of factors contributing to dry socket through enhanced fibrinolysis . J Oral Surg. 1979;37:42-46

[12]. Birn H.Bacteria and fibrinolytic activity in dry socket Acta Odontol Sand 1970;28:773-83

[13]. Houston JP, McCollum J, Pietz D, Schneck D. Alveola osteitis :a review of its etiology, prevention and treatment modalities . Gen Dent 2002;50:457-63

[14]. Birn H. Fibrinolytic activity of normal alveolar bone. Acta Odontol Scand 1971;29:141-53

[15]. Birn H.Fibrinolytic activity of normal alveolar bone. Acta Odontol Scand 1972;23-32

[16]. Daly B , Sharif MO , Newton T , Jones K , Worthington HV. Local interventions for the management of alveolar osteitis (dry socket). The cochrane Library 2012;12:1-30

[17]. Kolokythas A, Olech E , Miloro M . Alveolar osteitis : a comprehensive review of concepts and controversies. Int J Dent 2010;1-10

[18]. Birn H. Kinins and pain in dry socket . Int J Oral Surg . 1972;1:32-42

[19]. Muhammad AS. Pathogenesis and management of dry socket(alveolar osteitis). Pakistan Oral and Dental Journal Vol 30 , No.2(December 2010)

[20]. Sweet DB , Butler DP. Predisposing and operative factors:effect on the incidence of localized osteitis in mandibular third molar surgery. Oral Surg Oral Med Pathol 1978;46(2):206-213

[21]. Noroozi AR , Philbert RF. Modern concepts in understanding the management of the "dry socket" syndrome:comprehensive review of the literature. Oral Surg Oral Med Oral Pathol Oral Radiol Endod 2009;107:30-35

[22]. Silverstein P. smoking and wound healing.AmJ Med 93:22,1992

[23]. Mohammed H Abu Younis and Ra'ed O Abu Hantash. Dry Socket: Frequency, Clinical Picture, and Risk Factors in a Palestinian Dental Teaching Center.Open Dent J. 2011; 5: 7-12.

[24]. Fridrich , K.L, Olson , R.A. Alveolar osteitis following surgical removal of mandibular third molars. Anesth Prog 1990;(1)32-41

[25]. Lily GE , Osbon DB , Rael Em , Samuels HS , Jones JC . Alveolar osteitis associated with mandibular third molar extractions. JADA 1974:88:802-6

[26]. Soames JV; Southam JC (1999). Oral pathology (3. ed., [Nachdr.] ed.). Oxford [u.a.]: Oxford Univ. Press. pp. 296-298.

[27]. Bonine FL .Effect of chlorhexidine rinse on the incidence of dry socket in impacted mandibular third molar extraction sites Oral SurOralMed Oral Pathol Oral Radio Endol.. 1995 Feb;79(2):154-7; discussion 157-8.

[28]. Torres-Lagares D. Serera-Figallo MA, Romero-Ruiz MM , Infante-Cossio P, Garcia M, Gutierez-Perez JL. Update on dry socket : a review of the literature. Med Oral Patol Oral Cir Bucal 2005;10:81-85

[29]. NeugebauerJ, Jozsa M, Kübler A. Antimicrobial photodynamic therapy for prevention of alveolar ostitis and post-extraction pain. 2004 Nov;8(6):350-5. Epub 2004 Sep 29.

[30]. Kaya GS , Yapici G , Sarvas Z, Gungormus M . Comparison of alvogyl, Salicept patch and low level laser therapy in the management of alveolar osteitis. J Oral Maxillofac Surg 2011;69:1571-1577

[31]. Betts NJ , Makowski G, Shen YH , Hersh EV. Evaluation of topical viscous $2 \%$ lidocaine jelly as an adjunct during the management of alveolar osteitis. J Oral Maxillofac Surg 1995;53:1140-4

[32]. Schroff J , Bartels HA:Painful sockets after extractions. A preliminary report on the investigation of heir etiology , prevention and treatment (abstract). Dent Res J 9:81,1929

[33]. Ogini FO, Fatusi OA , Alagbe AO. A clinical evaluation of dy socket in a Nigerian population. Oral Maxillofac Surg. 2003.61:87176

[34]. Daly, B; Sharif, MO; Newton, T; Jones, K; Worthington, HV (Dec 12, 2012). "Local interventions for the management of alveolar osteitis (dry socket)

[35]. Turner PS. A clinical study of “dry socket”. Int J Oral Surg 1982;11:226-31 